\title{
SYNTACTIC OBJECT REPRESENTATIONS FOUND IN AWGNI SENTENCES
}

\author{
Berhanu Asaye Agajie \\ Department of Language Studies, Injibara College of Teachers' Education, P.O. Box 44 Injibara, Ethiopia
}

ARTICLE INFO

Keywords:

Labeling algorithm

Sentence

Syntactic object

$\{\mathrm{XP}, \mathrm{YP}\}$

Article History:

Received: $11 / 04 / 2020$

Accepted: 31/05/2020

Available Online:

$31 / 05 / 2020$

\begin{abstract}
Teachers and students in Injibara college were unable to understand syntactic object representations found in Awgni sentences. The motivation of this research was designed to fill the gap by analyzing syntactic object representations found in Awgni sentences. Henceforth, the objective of the study was to examine the Syntactic Object representations found within Awgni sentences classified by their function. A descriptive analysis was employed to interpret the sentence structures. The data were collected from the native speakers of Awi people ( 7 males, 6 females) based on their day-today outgoing acts, and from different texts. By purposive sampling, 23 sentences were selected, arranged, and described. The method of data analysis applied was Labeling Algorithm $\{X P, Y P\}$. Thus, raising XP Syntactic Objects has been modified and consequently, there is only one visible head. The result indicated that Awgni sentences in terms of their forms, forming, a causal relationship they contain were different. On the other hand, each sentence structure shares Syntactic Object representations that include NPs, VPs, DPs, PPs, ADVPs, and APs. Finally, the study recommended further research on how (LA) $\{H, X P\}$, and $\{X, Y\}$ works to describe the label of every Syntactic Object representations found within sentence structures in Awgni.
\end{abstract}

2442-305X/ (C) 2020 The Author, this is open access article under the (CC-BY-NC) license (https://creativecommons.org/licenses/by-nc/4.0/), DOI: 10.19105/ojbs.v14i1.3226

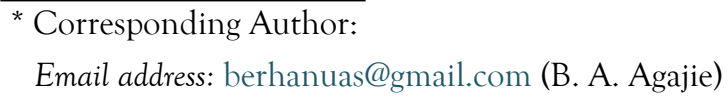

\section{A. Introduction}

Cushitic constitutes one of the six subgroups of the Proto-Afro-Asiatic family. It is mainly spoken in the area stretched along the Red Sea and around the vain of Rift Valley. The speakers mostly reside in North Eastern and Eastern Africa. The languages under this cluster are categorized into four: North, Central, East, and South. Central Cushitic (Agaw) has four clusters: Bilin, Khamatanga, Kimant, and Awgni. Agaw is a broad name given to four scattered Cushitic speaking groups of people in Ethiopia and Eritrea. They are the Bilen in Eritrea, the Kimant in Gander, the Xamtanga in Wag-Sekota, and the Awgni in Gojjam. ${ }^{1}$

\footnotetext{
${ }^{1}$ Robert Hetzron, The Verbal System of Southern Agaw (Berkeley: University of California Press, 1969); Tadesse Mengistu, "The Noun Phrase in Awgni" (MA Thesis, Addis Ababa University, 1984); Tamrat Tadesse, "Process of Ethnic Interaction and
} 
Regarding this issue, Gabor summarizes as:

"The Agaw (or Central Cushitic) languages and peoples, on which the earliest reference dates back to the first centuries $A D^{2}$, are scattered today in four main blocs: (1) Bilin in the area of the town Kärän in Eritrea, (2) in Ethiopia: Hamət Həməț people (sg. Hamra -Həmra) in the area of northern Wag, (3) Kemant of Kärkär and čəlga (north of Lake Tana), the Falasha or Betä Isra'el, (4) Awi (sg. Awiya) of Agäwmədər in Gojjam and the Kunfäl of the lowlands to the west of Lake Tana. Hamtanga and Awngi in Ethiopia and Bilin in Eritrea have regional language status."

The focus of this review is on southern Agaw called Awgni. Awgni is spoken by about one million people in Awi dispread area in northwest Ethiopia, together with all of Awi Zone, but also some areas of the Metekel Zone of the Benishangul Gumuz National Regional State, and various places in the Alefa and Kuwara Woredas of the North Gonder Zone of the Amhara National Regional State. The Alefa and Kuwara varieties have sometimes been called Kunfal but are dialects of the Awgni language. ${ }^{3}$

Grammatical structures in a given language reflect innate cognitive properties. Grammatical constructions, that are their formal properties such as whether they are finite or non-finite,

Integration in Ethiopian History: The Case of Agua," vol. 6 (the 9th International Coverage of Ethiopian Studies, Moscow: Nauka Publisher, 1988), 192206.

2 Takacs Gabor, "Agaw Lexicon and Its Cushitic and Afro-Asiatic Background," in The 5th International Conference on Cushitic and Omotic Languages, 2008.

3 Joswig Andreas, "The Phonology of Awgni," in SIL Electronic Working Papers, 2010. embedded, lack subjects, and so forth, systematically reflect their functions in managing discourse coherence. ${ }^{4}$

The syntax is a science which studies sentences, their structure, arrangement, and the relationship among words in a sentence. ${ }^{5}$ It has to do with how words are laid jointly to build phrases, with how phrases are put together to build clauses or bigger phrases, and with how clauses are put together to build sentences. ${ }^{6}$ Syntax attempts to give a set of rules that will correctly predict the combinations of words, which form grammatical sentences. $^{7}$ It seeks to describe exactly how structural relations between lexical items or words and operators in a sentence contribute to its interpretation. Syntax also looks to delineate closely all and merely those sentences that make up a given language using native speaker intuition. ${ }^{8}$ Thus, the job of syntax is to discover and formulate syntactic object representational principles that tell the way words are putting together to form grammatical phrases and sentences. ${ }^{9}$

\footnotetext{
${ }^{4}$ Noam Chomsky, "Minimal Computation and the Architecture of Language," Chinese Semiotic Studies 12, no. 1 (March 11, 2016): 13-24, https://doi.org/10.1515/css-2016-0003.

5 Miller Jim, An Introduction to English Syntax (Edinburg: Edinburg University Press, 2002).

6 Guglielmo Cinque, "Deriving Greenberg's Universal 20 and Its Exceptions," Linguistic Inquiry 36, no. 3 (July 1, 2005): 315-32, https://doi.org/10.1162/0024389054396917.

7 Miyoko Yasui, An Order-Free Representation of Syntactic Structure and the Head-Parameter (Dokkyo: Dokkyo University Press, 2006).

8 Spencer Andrew, Lexical Relatedness: A Paradigm-Based Approach (Oxford: Oxford University Press, 2013).

${ }^{9}$ Miguel Fuster Márquez, Working with Words: An
} 
Phrase is a syntactic object that contains more than one word and lacks the subject-predicate relationship. It contains some other single word or word group elements that specify, modify, or complete the headword in various ways. Thus; the basic units of syntax are words. They can be classified into different lexical categories based on meaning, morphological form, and syntactic function. ${ }^{10}$

Phrase has a hierarchical design in which words are grouped into successfully larger structural units. ${ }^{11}$ Henceforth, Syntactic Object Phrasal representations can be classified by the type of the head they take as: Prepositional Phrase (PP), Noun Phrase (NP), Verb Phrase (VP), Adjective Phrase (AP) and Adverb Phrase (ADVP). ${ }^{12}$ The predominant properties that characterize each particular variety of phrases, and which establish the role it plays are determined by the properties of the principal or headword that it includes. ${ }^{13}$ Depending on the number of constituents within the phrases to be analyzed, the sentence can be further broken down into XP, DP, TP, VP, DP, $N P, A D V P, A P, P P$, and a second phrase

Introduction to English Linguistics (Valencia: Universities de Valencia, 2011).

10 Andrew Carnie, Syntax: A Generative Introduction (Oxford: Willy Blackwell, 2013).

11 Martina Wiltschko, The Universal Structure of Categories (Cambridge: Cambridge University Press, 2014).

12 Andrew Carnie, Constituent Structure (Oxford: Oxford University Press, 2010).

13 Sandra Chung, "Are Lexical Categories Universal? The View from Chamorro," Theoretical Linguistics 38, no. 1-2 (January 10, 2012): 1-56, https://doi.org/10.1515/tl-2012-0001. type. ${ }^{14}$ Phrase structures are illustrated by the means of the tree diagram, which shows the structure of the Phrase. ${ }^{15}$ Phrase structure rules interpreted as an instruction to rewrite or expand the symbol on the left of the arrows as the sequence on the right. ${ }^{16}$

In the context of Awgni syntax, problems of projection in general, labeling algorithm, in particular, is a new incident and not introduced at all. Regarding labeling, two questions can be raised. The first is why labeling. Both Chomsky and Rizzi assume that every node in a syntactic tree must be labeled at the interfaces. According to Rizzi 'uniform labeling: at the interfaces, a tree must be completely labeled. ${ }^{17}$ The next question is what motivates such a requirement. Chomsky proposes that labeling is forced by requirements imposed by the external systems at the interfaces with syntax: ${ }^{18}$

"For a syntactic object (SO) to be interpreted, some information is necessary about it: what kind of object is it? Labeling is the process of providing that information. It is part of the process of forming a syntactic object SO. That is no longer true when the stipulations of these systems are eliminated in the simpler Merge-based conception of UG. We assume, then,

\footnotetext{
${ }^{14}$ Gisa Rauh, Syntactic Categories (Oxford: Oxford University Press, 2013).

${ }^{15}$ Andrew, Lexical Relatedness: A Paradigm-Based Approach.

${ }^{16}$ Radford Andrew, English Syntax: An Introduction. (Cambridge: Cambridge University Press, 2004).

${ }^{17}$ Luigi Rizzi, "Labeling, Maximality and the Head Phrase Distinction," The Linguistic Review 33, no. 1 (January 5, 2015): 1, https://doi.org/10.1515/ttr2015-0016.

18 Noam Chomsky, "Problems of Projection," Lingua, SI: Syntax and cognition: core ideas and results in syntax, 130 (June 1, 2013): 43, https://doi.org/10.1016/j.lingua.2012.12.003.
} 
that there is a fixed labeling algorithm LA that licenses SOs so that they can be interpreted at the interfaces, operating at the phase level along with other operations."

Moreover, in advancing the POP approach, Chomsky proposes that in syntactic structure, two items are combining by the operation Merge into a single set. ${ }^{19}$ It draws upon any two items $X$ and $\mathrm{Y}$, which creates an unordered twomember set. Merge $(X, Y)=\{X, Y\}$. Suppose neither $X$ nor $Y$ is part of the other, as in combining drink and water to form the syntactic object $\{X, \quad Y\}$ corresponding to drink water. Suppose that one is part of the other, say $Y$ is part of $X$. Then the result of Merge is again $\{X$, $Y$ \}. In this regard, I assume one major subcase of Merge to the task of labeling. ${ }^{20}$

19 Chomsky, "Problems of Projection"; Noam Chomsky, "Problems of Projection: Extension," in Structures, Strategies and Beyond: Studies in Honour of Adriana Belletti, ed. Elisa Di Domenico, Cornelia Hamann, and Simona Matteini (Philadelphia: Benjamin Publishing Company, 2014), 1-16, https://doi.org/10.1075/la.223.01cho; Noam Chomsky, "Recent Linguistics Talks by Chomsky: Lecturer 1," Whamit! (blog), June 3, 2014, http://whamit.mit.edu/2014/06/03/recentlinguistics-talks-by-chomsky/; Noam Chomsky, The Minimalist Program: 20th Anniversary Edition (Massachusetts: Massachusetts Institute of Technology, 2014); Chomsky, "Minimal Computation and the Architecture of Language."

${ }^{20}$ David Adger, "Roll-up, Roll-up, There Is Nothing to See" (Video Presentation, Baggett Lecture 2, University of Maryland, 2016) https://www.youtube.com/watch?v=UCJ1w0qAFNc; Chomsky, The Minimalist Program; Elly Van Gelderen, "Where Are the Parameters in Problems of Projection," ICHL 22 (July 31, 2015): 1-20; Eliot Murphy, "Reference, Phases and Individuation: Topics at the Labeling-Interpretive Interface," Opticon 1826 17, no. 5 (May 2015): 1-13, http://dx.doi.org/10.5334/opt.cn; Rizzi, "Labeling, Maximality and the Head - Phrase Distinction."
"Suppose $\mathrm{SO}=\{\mathrm{XP}, \mathrm{YP}\}$, neither a head. Here minimal search is ambiguous, locating the heads $\mathrm{X}, \mathrm{Y}$ of $\mathrm{XP}, \mathrm{YP}$, respectively. SO can be labeled by modifying $\mathrm{SO}$ that there is only one visible head. ${ }^{21}$

For an SO to be interpreted, however, it is necessary to know what kind of object it is. In $\{X P, Y P\}$, minimal search is ambiguous, locating (with equally minimal depth of search) each of the two heads $X$ and $Y$ of $X P, Y P$, respectively. It is assumed that such failure to identify a unique head in $\{X P$, YP\} prevents labeling, and since labels are required for interpretation at the conceptual-intentional interface $(\mathrm{Cl})$, if the object lacking the label appears at $\mathrm{Cl}$, it violates Full Interpretation. ${ }^{22}$

Chomsky argues that syntactic objects need to be labeled to get interpreted at the interfaces and also that Labeling Algorithm (LA) is just minimal search and a head, which is a computational atom, provides the label found by $\mathrm{LA}^{23}$ Therefore, sentence categories by the function must receive an interpretation at $\mathrm{Cl}$ SO must be labeled. ${ }^{24}$

${ }^{21}$ Chomsky, "Problems of Projection," 43.

22 Samuel Epstein, Hisatsugu Kitahara, and Thomas Seely, "Labeling by Minimal Search: Implications for Successive- Cyclic A-Movement and the Conception of the Postulate "Phase," Linguistic Inquiry 45, no. 3 (July 1, 2014): 463-81, https://doi.org/10.1162/LING_a_00163.

${ }^{23}$ Chomsky, "Problems of Projection."

24 Luigi Rizzi, "Notes on Labeling and Subject Positions," in Structures, Strategies and Beyond: Studies in Honour of Adriana Belletti, ed. Cornelia Hamann and Simona Matteini (Amsterdam: John Benjamins, 2015); ur Shlonsky and Luigi Rizzi, "Criterial Freezing in Small Clauses and the Cartography of Copular Constructions: Theoretical Approaches and Empirical Domains," in Freezing (Geneva: University of Siena, 2015), 29-65, https://doi.org/10.1515/9781501504266-002. 
Thus, the way of labeling is defined by modifying SO (by raising XP) so that there is only one visible head as in: ${ }^{25}$

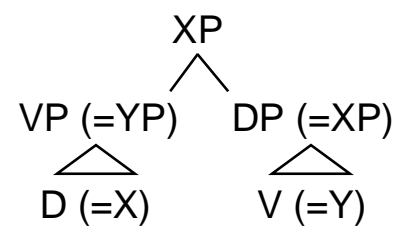

Then the Labeling Algorithm 'sees' $Y P$, but not $X P$, which is the lower part of a discontinuous element, a chain consisting of a series of copies headed by the structurally most prominent element. It is required that a category be assigned, and the choice is stipulated to be $\mathrm{Y}=\mathrm{V}$, the verbal head of the predicate, clearly the desired outcome.

In set $\{X P, Y P\}$ if $X P$ rises, this Phrasal movement $(X P)$ can only involve maximal objects with a given label. ${ }^{26}$ Thus, the maximal XP immediately overlooks the same label XP. Suppose XP raises, and then the result will be the structure is $X P$ copula $\left\{D P{ }_{X P}, Y P\right\}$, with two copies of XP. The intuitive idea is that the lower XP (subscript) copy is invisible to $L A$, since it is part of a discontinuous element. Therefore, DP will receive the label of YP. Given this, I make the concrete proposal to accumulate the instance of $\{\mathrm{XP}, \mathrm{YP}\}$ that arises in actual derivation. ${ }^{27}$

Moreover, categories such as DP (Determiner Phrase), CP (Complementizer Phrase), TP (Tense Phrase), VP (Verb Phrase), AP (Adjective

25 Chomsky, "Problems of Projection"; Chomsky, "Problems of Projection: Extension"; Chomsky, The Minimalist Program.

${ }^{26}$ Rizzi, "Notes on Labeling and Subject Positions."

${ }^{27}$ Chomsky, "Problems of Projection."
Phrase), ADVP (Adverb Phrase), and PP (Preposition Phrase) are used for expository convenience as in: ${ }^{28}$

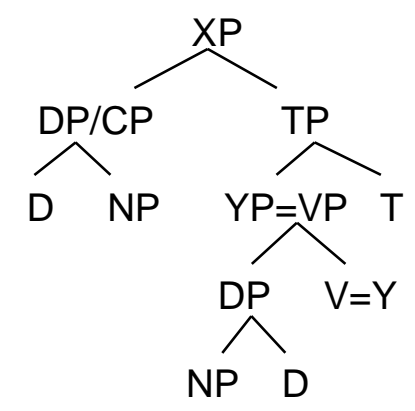

In the above model, merge combines two Syntactic Objects, for example, DP and TP to form a set (DP, TP\} from them. This creates a new SO $X P$, which is different from its members. $X P$ has no relation between DP and TP. Furthermore, the DP internally merged with TP later in the derivation after $T$ is introduced into the structure. Thus, VP determines the label of $\mathrm{YP}$, at this point because of the unique element that $\mathrm{YP}$ contains. A structurally most prominent member is V. Hence, only $Y P$ is visible to the labeling algorithm and the structure is labeled as $\mathrm{V}$, which is verbal, the desired outcome. However, auxiliary verbs might take place at the final stages of sentence structure. On this occasion, they keep in touch with $T$ position and only help the main Verb that comes ahead of it. In Awgni, the subject (including interrogative case) must be visible in $\{D P, T P\}$.

Sentential elements such as complementizers, sentence-final particles, aspect, tense, focus and topic, and agreement morphemes, and determiners are not the head of that phrase, which should rather be taken to be silent.

\footnotetext{
${ }^{28}$ Chomsky.
} 
Moreover, Awgni rejects syntactic object movements as a Syntactic Operation, since they never have semantic effects (Cinque, ${ }^{29}$ Lechner, $^{30}$ and Roberts ${ }^{31}$ ). Moreover, an assumption that is implicit in the analyses, which I have presented here, is that tree structure of all sentences is derived (i.e. formed) in a bottom-up fashion, (i.e. they are built up from bottom to top).

Yimam $^{32}$ and Amhare $^{33}$ have been studied one of Ethiopian language Amharic Syntax in depth. Their books were intended to analyze sentence structures based on X-bar syntax. This study is on Labeling Algorism was much younger than studies in X-bar theory. The current research was based on Labelling Algorithm (LA). Syntactic object representations found within sentence projection in general, the labeling algorithm, in particular, is new knowledge and not introduced in Ethiopia. Therefore, this study intended to apply how Labeling Algorithm works to label Syntactic Objects found in Awgni sentences within their function. In this regard, Chomsky's ${ }^{34}$ supposes that in Syntactic Object $\{X P$, YP\} neither a head is ambiguous to locate

${ }^{29}$ Cinque, "Deriving Greenberg's Universal 20 and Its Exceptions."

${ }^{30}$ Winfried Lechner, "Interpretive Effects of Head Movement," in Phases of Interpretation, ed. Mara Frascarelli (Berlin: Mouton de Gruyter, 2006), 4571.

${ }^{31}$ Ian Roberts, Agreement and Head Movement: Clitics, Incorporation, and Defective Goals (Cambridge: MA: MIT Press, 2010).

${ }^{32}$ Baye Yimam, Amharic Grammar (Addis Ababa: E.M.P.D.A, 1986).

${ }^{33}$ Amhare Getahun, Modern Amharic Grammar: In Simple Approach (Addis Ababa: Trade Printing House, 1990).

${ }^{34}$ Chomsky, "Problems of Projection: Extension." the head $\mathrm{X}, \mathrm{Y}$, of $\mathrm{XP}$, YP respectively. Thus, labeling algorism (LA) is problematic. It sought to do so by modifying Labeling Algorithm $\{\mathrm{XP}, \mathrm{YP}\}$. Therefore, the study tried to address what kind of Syntactic Object representations found within sentences classified by purpose. Thus, it will explore Syntactic Object representations found within sentences classified by purpose.

\section{B. Method}

The study used a descriptive research design. Its rationale is to supply the structure of sentences as they logically occurred and to demonstrate how Syntactic Object was represented in the tree. Through purposive sampling, 13 respondents ( 7 male, 6 female) were selected to crosscheck the data. The sample was selected as representative samples who could provide valuable information to achieve the intended objective. This Language and linguistic knowledge-based judgmental informant selections were used to collect valuable data to achieve the research objective.

The data were collected from the native speakers of Awi based on their day-to-day communicative acts, and from different texts. Based on the functional category, the layout, and the length of data 23 sentences were chosen for analysis. The method of data analysis engaged in this study was Labeling Algorithm $\{X P, Y P\}$. As a result, $L A$ modifies Syntactic Object by raising $X P$, and then there would be only one visible Verbal head. 


\section{Results}

Grammatical structures reflect innate cognitive properties. ${ }^{35}$ Grammatical constructions, that are their formal properties such as whether they are finite or non-finite, embedded, lack subjects, and so forth, systematically reflect their functions in managing discourse coherence.

Thus, a sentence is a group of words containing a subject and a predicate expressing a complete and independent unit of thought. ${ }^{36}$ It is seen as hierarchies of interconnecting smaller units, or constituents. Based on the functional classification there exist declarative, interrogatives, imperative, and exclamatory sentence types. Therefore, this part of the study presents Syntactic Object representations found within declarative, interrogative, imperative, and exclamatory sentences.

\section{Structure of Declarative Sentences}

Declarative sentences of Awgni have a word order of subject and objects plus verb (SOV), which is the underlying structure used for this analysis. ${ }^{37}$

35 Chomsky, "Minimal Computation and the Architecture of Language."

${ }^{36}$ Finch Geoffrey, Key Concepts in Language and Linguistics (New York: Palgrave Macmillan, 2005), 109.

${ }^{37}$ Yimam, 224.
(1) Tinsae doctera taxuxa Tinsae doctor became 'Tinsae became a doctor'

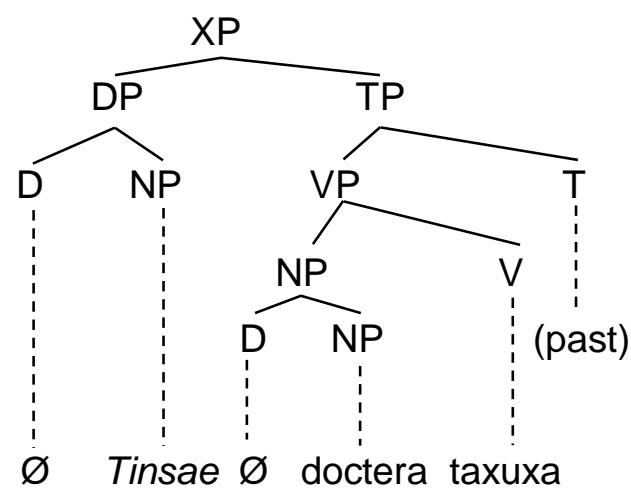

In the aforementioned structure (1), Tinsae doctera taxuxa, the head of the sentence taxuxa is the copular verb that makes use of to talk about the change in which Tinsae becomes a doctor. Furthermore, the Noun Phrase (NP) doctera function as object is the complement of the verb taxuxa. In the same token, Tinsae is the subject of the sentence.

(2) Alazar lïgda yaxuxa

Alazar handsome became

'Alazar became handsome'

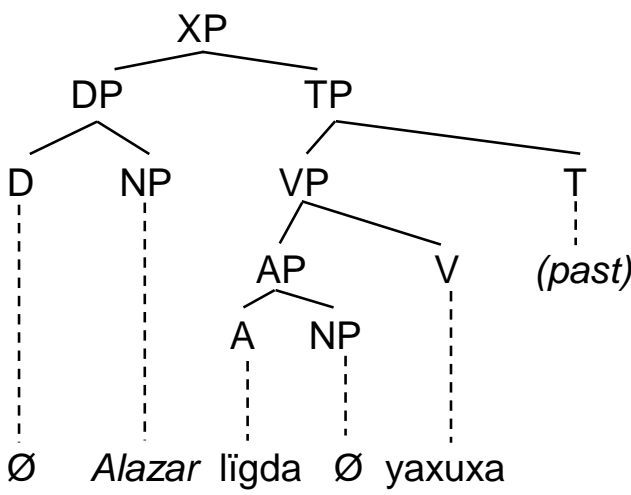

The resulting copulative sentence structure (2) Alazar lïgda yaxuxa is headed by the verb yaxuxa. Adjective ligda is the complement of yaxuxa. The Noun Phrase (NP) Alazar is the subject of the sentence. The copular verb like 
yaxuxa in Awgni indicates the characteristics of the subject in a given sentence structure.

(3) Ïn Yared ničusta yaxuxa

This Yared like his mother became

'Yared became like his mother'

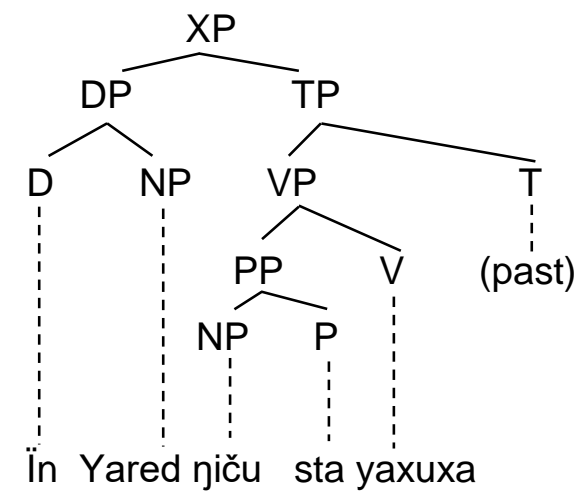

Example (3) shows that the Determiner Phrase în yared is the subject of the sentence; Prepositional Phrase $(\mathrm{PP})$ is also the immediate compliment of the head Verb yaxuxa. On the other hand, sta under Prepositional Phrase (PP) states similarity, which exists between Yared and niču.

In Awgni, the verb is transitive: (1) if the coordination of VP is either with a verb or a preposition, (2) the determiners like [e], [wa] and [-o] are added, and (3) when the object receives the action. Based on these projections, verbs like xuxa/ ate tasxo/ kicked dïxutuxa/ told yitxo/ gave gïšxo / digging and others are transitive. Verbs, which show the event of transferring an action from doer (subject) to the receiver, need both Prepositional Phrase and Noun Phrase as immediate complement.
(4) Wuliji aqi sato Helens šelemaya The old man the watch for Helen not awarded

'The old man wasn't awarded the watch for Helen'

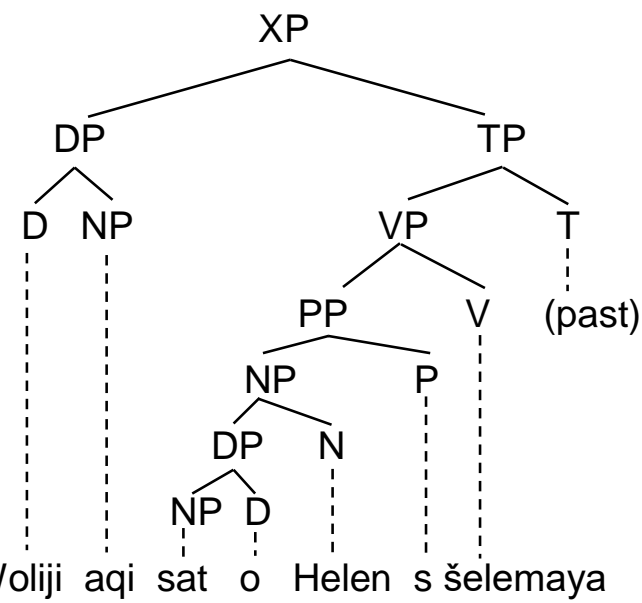

In(4), Wuliji aqi sato Helen šelemaya is the negative sentence that tells us the event of watch awarding has not taken place or is not taking place. This structure contains both direct and indirect object. Sato is the direct object and it refers that the old man was not awarded. Alternatively, Helens are the indirect objects which refer to whom he does not award. The subject of the sentence is wuliji aqi. The head of the overall sentence structure is the verb šelemaya.

(5) Xsanti aqi nïnda zïko

The big man in the house live 'The big man lives' in the house'

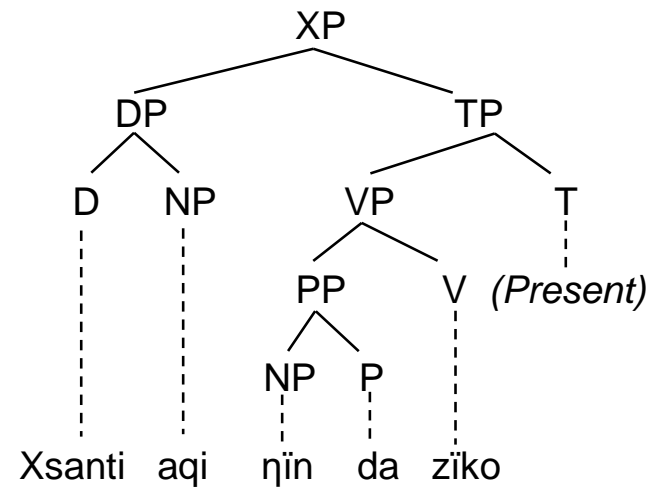


What (5), tells us is that xsanti aqi nïnda zïko is existential sentence structure used to refer to a specialized or non-canonical construction, which expresses a proposition about the existence or the presence of xsanti aqi. Thus, the preceding sentence considered as existential because it is specialized, and entails nothing other than the existence of the Determiner Phrase xsanti aqi. Furthermore, xsanti aqi is the subject of the sentence; ziko is the head of the entire sentence. The prepositional Phrase nïnda is the complement of the head.

\section{Structure of Interrogative Sentences}

Interrogative sentences, ask questions. The tones might be about the subject, complement, or events stated in a verb. Words, which are used to ask questions include ay/ who, ïndara/ what, wani/ when, watna how, ïndarsil why and so on ${ }^{38}$ as in:

(6) Mulualem ïndaray jewux?

Mulualem what buy

What did Mulualem buy?

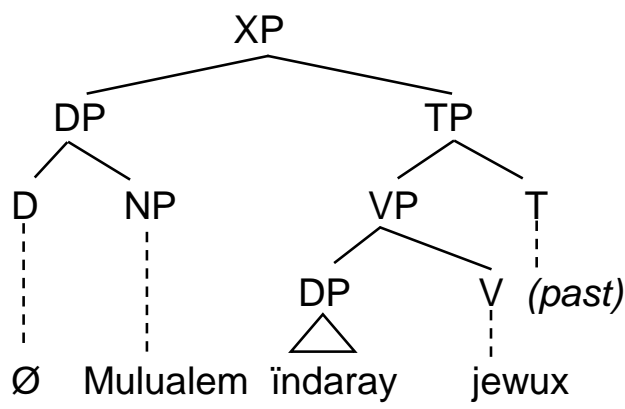

What example (6) notifies is that the overall expression Mulualem ïndaray jewux is an interrogative sentence; its head is the verb jewux, and the complement of jewux is the DP/
Determiner Phrase ïndaray: The subject of the entire sentence is DP phrase Mulualem. Moreover, the VP Mulualem indaray jewuxis a projection of the head Verb jewux.

(7) Šaše darmas bardardes tintux? Šaše by what means from Bahir Dar came

'By what means did Šaše come from Bahir Dar?'

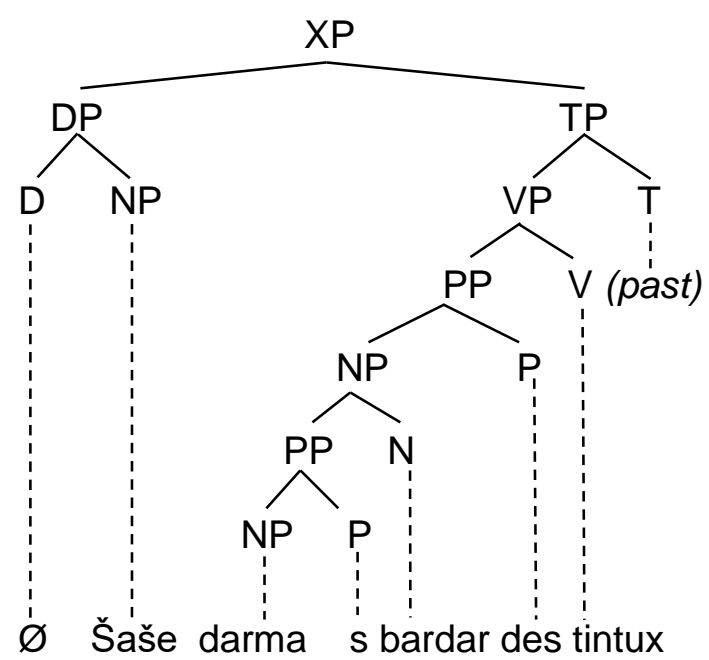

The terminal Verb tintux in (7) has a complement, which declared in darmas. The word darmas replaces the Prepositional Phrase, which is the immediate complement for the Verb tintux. The Prepositional Phrase Barders conjoined with the Verb Phrase tintux to modify the intended Verb. Indeed, Šaše is the subject of the given structure.

\footnotetext{
${ }^{38}$ Yimam, 238.
} 
(8) Alemu ničuli kïmus ïrbato xuxama? Alemu with his mother in the evening his dinner eat

'Did Alemu eat his dinner with his mother in the evening?'

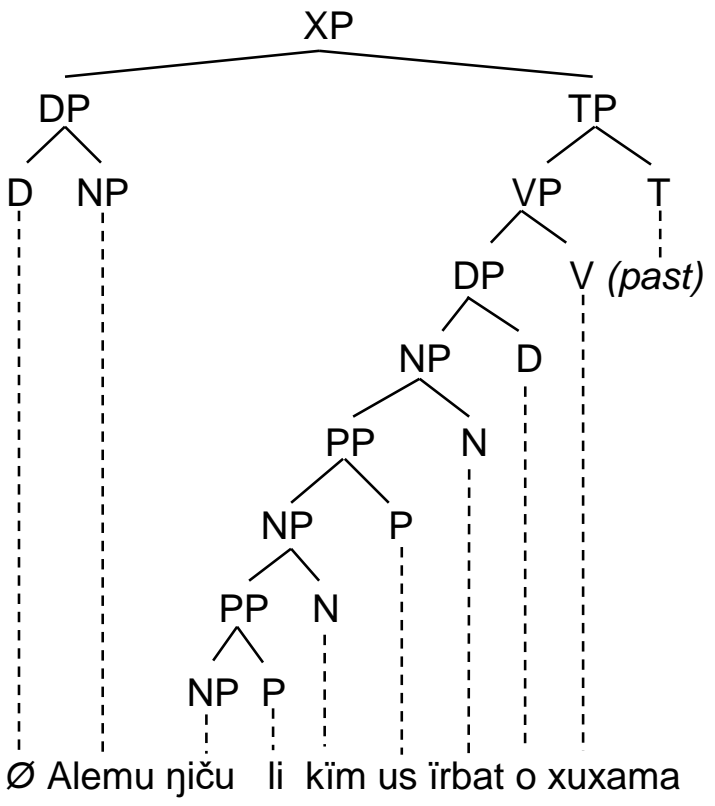

What the tree in (8) tell us is that Alemu ničuli kïmus ïrbato xuxama is general question that the speaker is interested to know whether Alemu eat his dinner with his mother in the evening. Alemu and ïrbato are Noun Phrases, whose functions are being a subject and object respectively. The Verb xuxama is the head of the overall sentence structure. Conversely, the Prepositional Phrases (PPs) pičuli and kïmus have a descriptive function.
(9) Agalu ničuli wani ïrbato xux? Agalu with his mother when his dinner ate

'When did Agalu eat his dinner with his mother?'

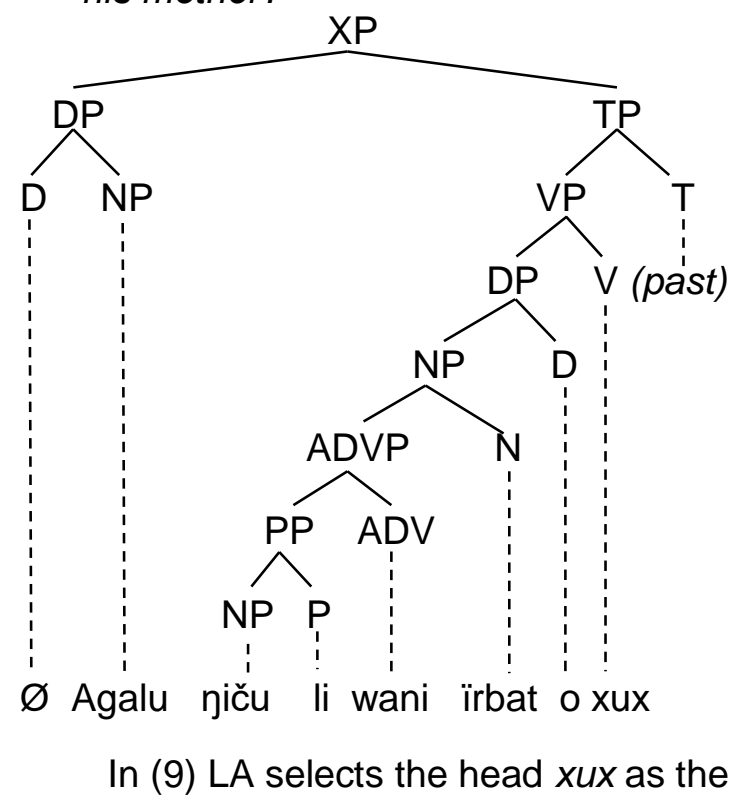
head of the overall sentence structure. Agalu is the subject of sentence. The main objective of the above questions is to address the nature and the structure of Prepositional Phrases (PPs). Hence, pronouns like ali and wani are conjoining with Prepositional Phrase. Finally, one can raise a question, which states the Verb as in:

(10) Agalu ïndaray akomečīxu? Agalu what performed 'What did Agalu perform?'

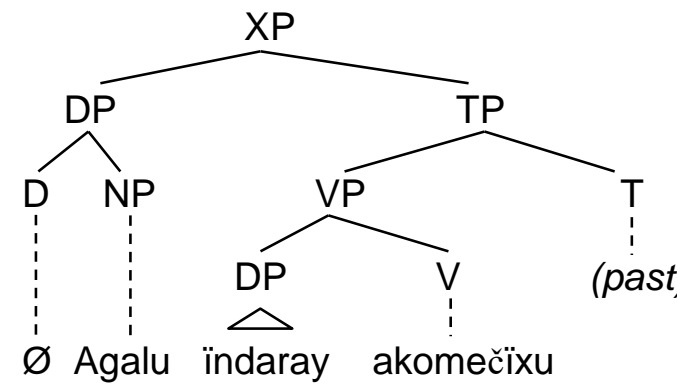

Under the analysis in akomečïu is an action Verb. It tells that something is happening. As a result, any verb can replace it in the structure. The 
verb found in the place of transitive verb needs immediate complement. It replaces the object of sentence structure. Ïndaray is the immediate complement for the projected head. It also reveals that Agalu and ïndara belong to the category DP, that is, they are Determiner Phrases, and that akomeciixu belongs to the category VP or is a verb phrase, consisting of a verb. It also reveals the syntactic category of each of the words in the sentence.

(11) Bitäw yintawuma?

Bitäw will come

'Will Bitew come?'

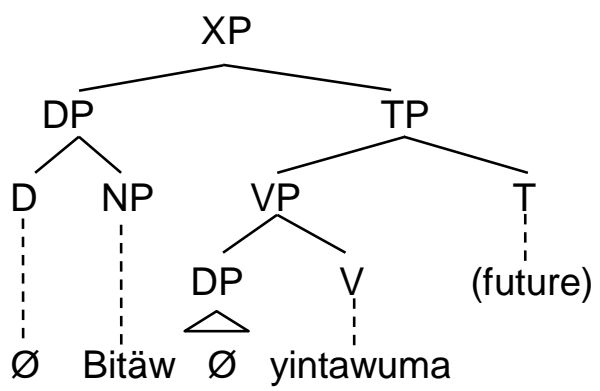

In (11) the head verb yintawuma in above sentence enables the speaker to check whether the event will happen or not. The speaker of the sentence needs to assured to the actual journey performed by Bitäw. The listener ought to inform the event for someone who raises the question.

(12) Kassa ïndaray kantïxu? Kassa what did saw 'What did kassa saw?'

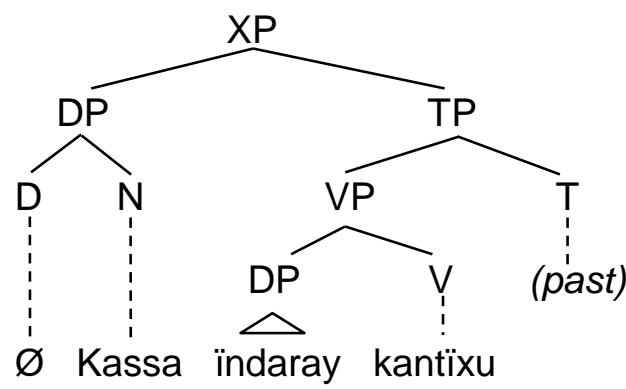

As shown in (12), the visible head of the entire sentence is the verb kantïxu and its complement is Determiner Phrase indaray. Seemingly, the complete sentence structure was conjoined out of the subject kassa, the Noun Phrase (object) ïndaray immediately followed by Verb Phrase kantïxu. The question is about the complement. The speaker wants to know what Kassa was seen in the past.

\section{Structure of Imperative sentences}

Imperative sentences articulate guidelines, orders, requests, advice, suggestions, and other events. Indeed to eloquent a command or a request, or to prohibit an action, imperative sentences can be used. Adults do not usually give each other orders, unless they are in a position of authority. However, adult can give orders to children. ${ }^{39}$ The information of order is important; each word is stressed the falls at the beginning of sentences as in (13) and (14):

(13) Dïšï tušie xataw!

Now the bread bring

'Bring the bread now!'

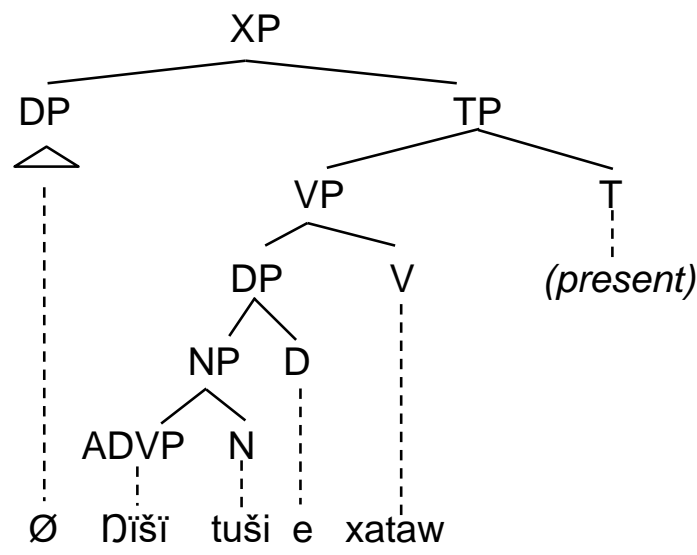

${ }^{39}$ Yimam, 224 
In accordance with (13), the stressed words are gï̌ï tušie and xataw. Thus, the tone falls on nïsii. It addresses a very rude command or order. Noticeably, the speaker's goal is to induce the hearer to bring bread. The sentence is about a present action of the hearer, the hearer should (intentionally) act in such a way that the propositional content of the illocutionary act is made true. The speaker expresses her or his desire or wishes that the hearer brings bread and the speaker seems to assume that the hearer is able to bring bread.

Tušie xataw is imitative sentence structure conjoined from head Verb xataw and its complement $\eta \ddot{s} s ̈$ tušie. The subject of the sentence is marked as empty. This is the case that, subject in each imperative sentence is understood and pointed in the structure as $\varnothing$. Thus, the subject was pronoun ïnt/ you that stand for second person intended for either feminine or masculine in gender, and singular in number. The subject takes place when it can be determined in the grammar of speaking as in (14):

(14) Ïnt kobie xataw! You the pen bring 'You, bring the pen!'

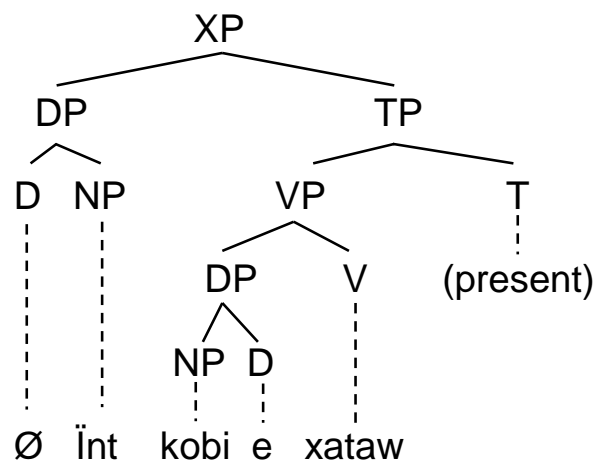

The resulting structure in (14) contains two major constituents, the subject Determiner Phrase ïnt and the Verb Phrase kobie xataw. The Determiner Phrase kobie and the verb xataw hanged immediately under the Verb Phrase (VP). Kobie is the object that serves as immediate complement for the head Verb xataw. The one who gives command and who receives the message in a given context can determine the meaning of each sentence in oral level. The subject of a sentence can appear when the event told in a stressed manner.

(15) Di tušie tuštïs! She the bread to beak 'Let her beak the bread!'

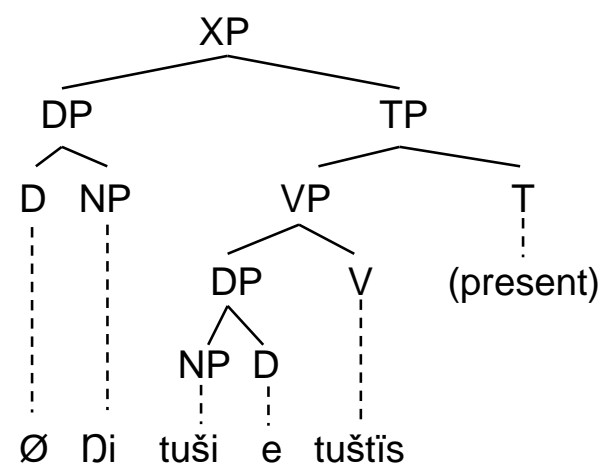

What the tree in (15) tells us is that the jussive mood in Awgni serves as an imperative (for using orders, commanding or requesting orders, commanding or requesting), which covers the third person. The command was an unknown person or in the third part. The subject of the given sentence is the pronoun $n i$, the head of the entire sentence is tuštïs and its complement is tušie.

Imperatives can be used to warn someone of danger. All the words in the warning one are stressed, but the first word has a higher tone than the last one as in (16) and (17): 
(16) Dïši wonberda ïnjiku! Now on the chair sit down 'Sit down, on the chair now!'

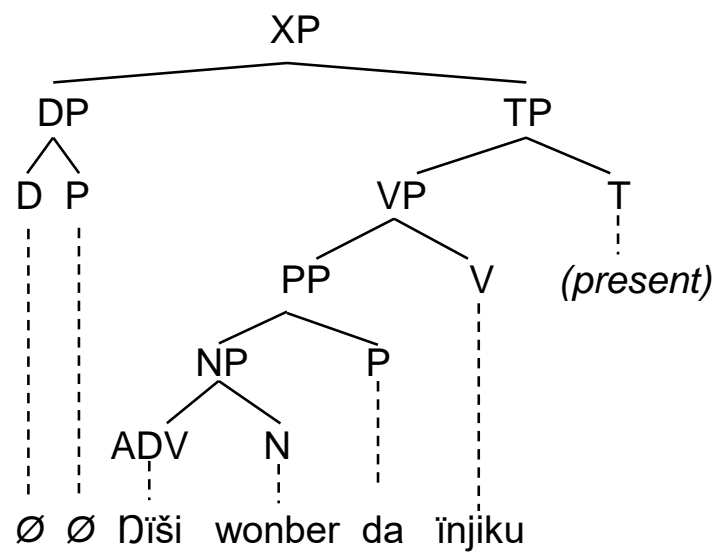

Analysis (16) accounts that; the subject of the entire sentence is empty. The head of the overall sentence structure is ïjiku. The first word has a higher tone than the head word. Dïsi wonberda is the complement of the Verb ïnjiku.

(17) Ïnt dado kepeki!

You the road do not cross

'You do not cross the road!'

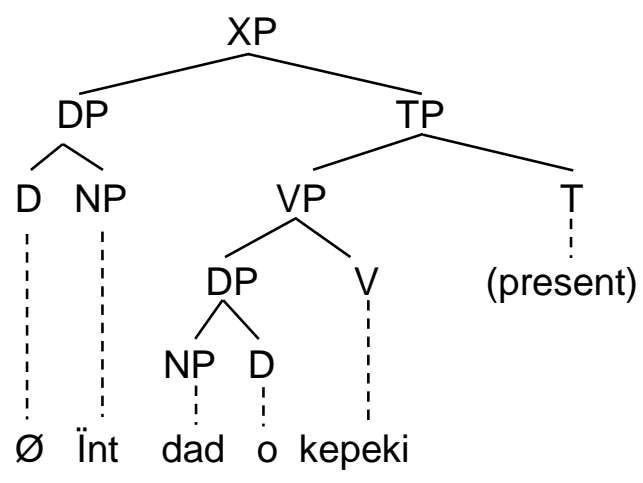

Datum (17) tells us is that the subject of the entire sentence is the pronoun int and the head of the overall sentence is kepeki. Dado is the complement of the head word. The sentence conveys a piece of advice given to somebody to be careful or to stop doing the crossing.
When advice is given to someone, the words in sentences are stressed as in (18) and (19):
(18) Ïnt lego nekŝeki! You the fire do not touch 'You do not touch the fire!'

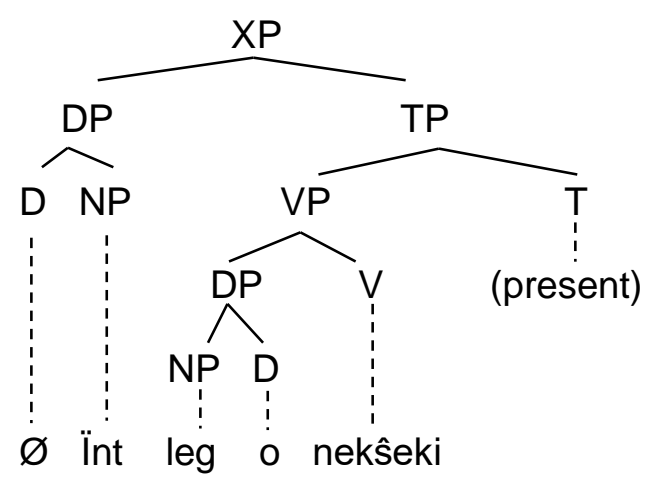

The resulting structure in (18) depicts that, nekŝeki is the transitive verb that gives advice he or she not to put his or her body in contact with the fire. The subject of the sentence is the pronoun ïnt. The head of the overall sentence structure is the Verb nekseki. The Determiner Phrase lego is the complement of the head.

(19) Ïnt yizkuka dibkawa buyeki! You heavy things do not carry 'You do not carry heavy things!'

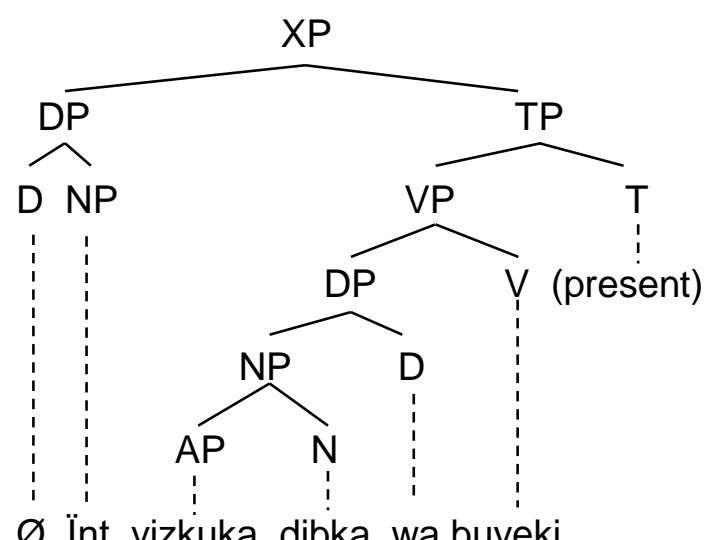

In (19) ïnt yizkuka dibkawa buweki is the projection of the verb buweki. It 
conjoined with Determiner Phrase yizkuka dibkawa. The subject of the overall sentence structure is pronoun int. The head of the entire sentence structure is the verb buyeki.

One can also use imperative sentences to make a request, but polite words were used before the Verb. Note that imperative sentences do not require the subject. Thus, the implied subject is you as in:

(20) Ader ïnda tïšiŝeki!

Please this do not smoke

'Do not smoke here, please!'

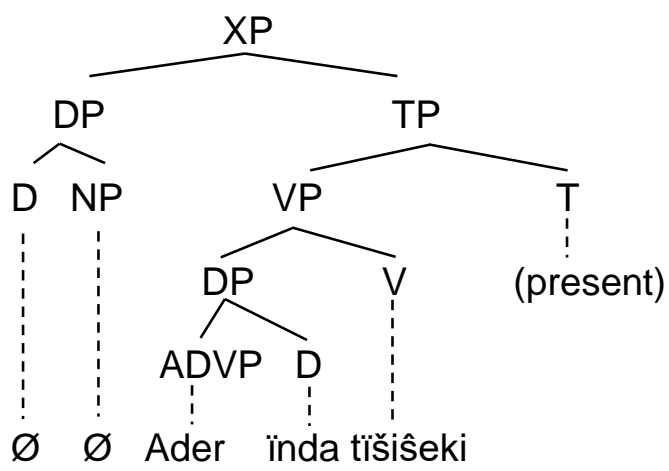

What (20) tells us is that Ader ïnda tï̌iseki is the projection of the head tissitseki. The determiner Phrase adder inda is the complement of the head tï̌siŝeki.

\section{Structure of Exclamatory Sentences}

Exclamatory sentences expressed joy, sorrow, regret, surprise, wonder, anger, excitement, and other strong feelings. One way of defining exclamatory sentences is by form. Form has to do with sentence word arrangement. To be an exclamatory sentence in form, Awgni sentences begin with how and what as in (21) and (22):
(21) Watna ïnkanstaw gerk yaxux! What kind nice day is 'What a nice day it is!'

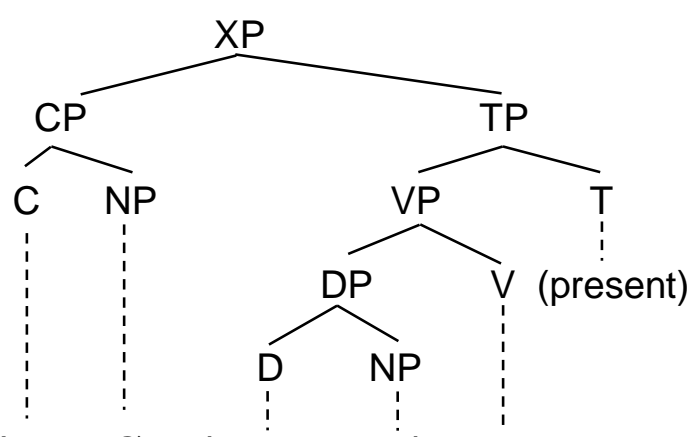

Watna $\varnothing$ inkanstaw gerk yaxux

The bar notation used in (21) posits that the intended sentence expresses exciting feedback on the state of affairs. Case in point, Watna ïnkanstaw gerk yaxux notifies not only that it is a nice day, but also the speaker exceedingly pleased by it. Yaxux is the only one visible head of the completely exclamatory sentence structure.

(22) Xïra gobeza kïntanta ïštixo! Xira active student was 'Xira was an active student!'

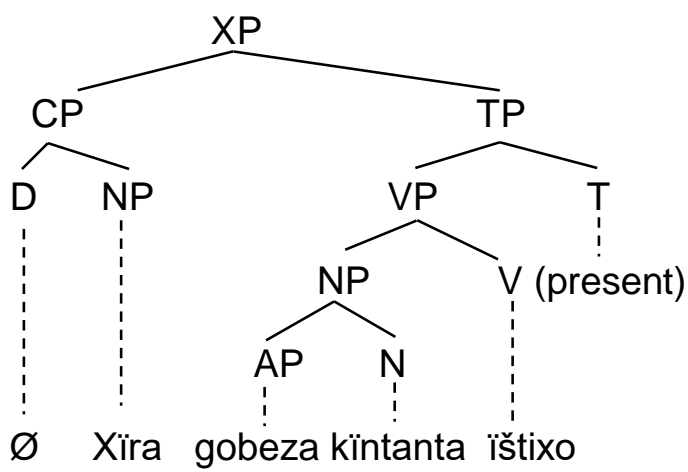

Determiner Phrase Xira in data (22) is the subject of the sentence. The speaker of this sentence expressed his or her surprise, excitement, or a strong feeling of the context that Xira was a cleaver student in the past. The Verb Phrase was conjoining with the structure of Determiner Phrase gobeza kïntanta and the head verb ïštixo. 
(23) Wataqowusa dingule ïllo ŝata! What big the eyes have 'What big eyes you have!'

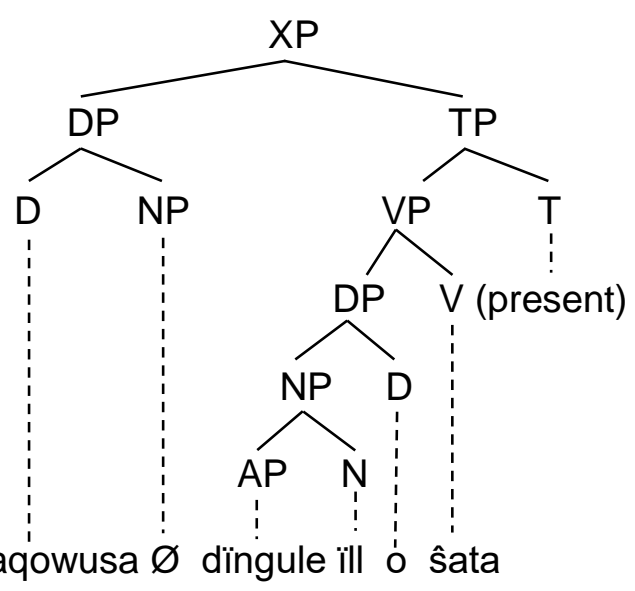

What tree (23) says is that the head of the resulting exclamatory sentence projection wataqowusa dingule ïllo sata is the verb sata, and the Determiner Phrase dingule ïlo is the complement.

The research finding on Syntactic Object representations found in Awgni sentences was consistent with the result of Chomsky's previous study ${ }^{40}$ that Syntactic Objects have to hold information concerning what kind of Syntactic Objects they are. Current research in Awgni approved the assumption it follows that any newly created SO by Merge must also contain label. In this way, the intended and previous study emphasized that the label of SO is determined at the phase level. These researches go on to argue that the label of $\mathrm{SO}$ is determined by the operation Labeling Algorithm (LA). Like Chomsky's assumption, ${ }^{41}$ the result from

40 Noam Chomsky, "Notes on Denotation and Denoting," in From Grammar to Meaning, by Caponigro and C. Checchetto (Cambridge: Cambridge University Press, 2013), 38-46, https://doi.org/10.1017/CBO9781139519328.004.

${ }^{41}$ Chomsky, "Problems of Projection: Extension." the present study shows that Syntactic Object $\{X P, Y P\}$, neither a head then minimal search is ambiguous, finding both the head $X$ of $X P$ and the head $Y$ of $Y P$. To solve this ambiguity, LA defines labeling through modifying $\mathrm{SO}$ (by raising $\mathrm{XP})$ so that there is only one visible head. Then the labeling algorithm looks YP, which is the lower part of a discontinuous element, a chain consists of a succession of copies headed by structurally most important element.

Like Shlonsky and Luigi study the primary supposition in the present study was that syntactic trees must be uniformly labeled at the interfaces. ${ }^{42}$ Constant labeling can be a product of interpretive principles, which may need labels to be properly interpreting structure. The second postulation that I use Chomsky's study was that the labeler of a category created by Merge was $\{\mathrm{XP}, \mathrm{YP}\}$ case, defined by $L A$ that modifies $S O$ by raising $\mathrm{XP} .{ }^{43}$ The result of this study corresponds with Adger was that the verb $(\mathrm{V})$, which is found at the end of sentence structure, is the only one visible head for the entire So. ${ }^{44}$

The main difference between this study and the above researches was sentential elements such as complementizers, sentence-final particles, aspect, tense, focus and topic, and agreement morphemes, and determiners in Awgni are not actually the head of that

\footnotetext{
${ }^{42}$ Shlonsky and Rizzi, "Criterial Freezing in Small Clauses and the Cartography of Copular Constructions."

${ }^{43}$ Chomsky, "Problems of Projection: Extension."

44 Adger, "Roll-up, Roll-up, There Is Nothing to See."
} 
phrase, which should rather be taken to be silent. Furthermore, akin to Cinque ${ }^{45}$, Roberts $^{46}$ and Hartman ${ }^{47}$ investigation Awgni rejects syntactic object movements as a syntactic operation since they never have semantic effects.

\section{Conclusion}

The result showed that syntactic trees were uniformly labeled at the interfaces. Thus, completely labeled Syntactic Object representations bring into being in declarative, exclamatory, interrogative, and imperative sentences shared similar Syntactic Object structure. Thus, XP has Determiner Phrase (DP) and Tense Phrase (TP). Every head, projects a larger syntactic unit (XP), and each sentence structure has one head. This postulation captured that the head of each Awgni sentence was the Verb. Syntactic Object representations originated in each type of sentence structure shared phrasal categories like NP, VP, PP, DP, AP, and ADVP.

\section{Recommendation}

The study suggests further research on how Labeling Algorithm $\{X P$, $H$, and $\{X, Y\}$ work to label Syntactic Object representations found in Awgni sentence categories classified by function.

\footnotetext{
${ }^{45}$ Cinque, "Deriving Greenberg's Universal 20 and Its Exceptions."

${ }^{46}$ Hetzron, The Verbal System of Southern Agaw.

47 Jeremy Hartman, "The Semantic Uniformity of Traces: Evidence from Ellipsis Parallelism," Linguistic Inquiry 42, no. 3 (July 2011): 367-388, https://doi.org/10.1162/LING_a_00050.
}

\section{References}

Adger, David. "Roll-up, Roll-up, There Is Nothing to See." Video Presentation presented at the Baggett Lecture 2, University of Maryland, 2016. https://www.youtube.com/watch?v= UCJ1w0qAFNc.

Andreas, Joswig. "The Phonology of Awgni." In SIL Electronik Working Papers, 2010.

Andrew, Radford. English Syntax: An Introduction. Cambridge: Cambridge University Press, 2004.

Andrew, Spencer. Lexical Relatedness: A Paradigm-Based Approach. Oxford: Oxford University Press, 2013.

Carnie, Andrew. Constituent Structure. Oxford: Oxford University Press, 2010.

. Syntax: A Generative Introduction. Oxford: Willy Blackwell, 2013.

Chomsky, Noam. "Minimal Computation and the Architecture of Language." Chinese Semiotic Studies 12, no. 1 (March 11, 2016): 13-24. https://doi.org/10.1515/css-20160003.

"Notes on Denotation and Denoting." In From Grammar to Meaning, by Caponigro and C. Checchetto, 38-46. Cambridge: Cambridge University Press, 2013. https://doi.org/10.1017/CBO978113 9519328.004.

. "Problems of Projection." Lingua, SI: Syntax and cognition: core ideas and results in syntax, 130 (June 1, 2013): 33-49. https://doi.org/10.1016/j.lingua.2012. 12.003.

"Problems of Projection: Extension." In Structures, Strategies and Beyond: Studies in Honour of Adriana Belletti, edited by Elisa Di Domenico, Cornelia Hamann, and Simona Matteini, 1-16. Philadelphia: Benjamin Publishing Company, 2014. https://doi.org/10.1075/la.223.01cho. 
- "Recent Linguistics Talks by Chomsky: Lecturer 1." Whamit! (blog), June 3, 2014. http://whamit.mit.edu/2014/06/03/rec ent-linguistics-talks-by-chomsky/.

- The Minimalist Program: 20th Anniversary

Edition.

Massachussetts: Massachussetts Institute of Technology, 2014.

Chung, Sandra. "Are Lexical Categories Universal? The View from Chamorro." Theoretical Linguistics 38, no. 1-2 (January 10, 2012): 156. https://doi.org/10.1515/tl-20120001.

Cinque, Guglielmo. "Deriving Greenberg's Universal 20 and Its Exceptions." Linguistic Inquiry 36, no. 3 (July 1 , 2005): 315-32. https://doi.org/10.1162/0024389054 396917.

Epstein, Samuel, Hisatsugu Kitahara, and Thomas Seely. "Labeling by Minimal Search: Implications for SuccessiveCyclic A-Movement and the Conception of the Postulate “"Phase."'” Linguistic Inquiry 45, no. 3 (July 1, 2014): 463-81. https://doi.org/10.1162/LING_a_001 63.

Gabor, Takacs. "Agaw Lexicon and Its Cushitic and Afro-Asiatic Background." In The 5th International Conference on Cushitic and Omotic Languages, 2008.

Gelderen, Elly Van. "Where Are the Parameters in Problems of Projection." ICHL 22 (July 31, 2015): $1-20$.

Geoffrey, Finch. Key Concepts in Language and Linguistics. New York: Palgrave Macmillan, 2005.

Getahun, Amhare. Modern Amharic Grammar: In Simple Approach. Addis Ababa: Trade Printing House, 1990.

Hartman, Jeremy. "The Semantic Uniformity of Traces: Evidence from Ellipsis Parallelism." Linguistic Inquiry 42, no. 3 (July 2011): 367-
388.

https://doi.org/10.1162/LING_a_000 50.

Hetzron, Robert. The Verbal System of Southern Agaw. Berkeley: University of California Press, 1969.

Jim, Miller. An Introduction to English Syntax. Edinburg: Edinburg University Press, 2002.

Lechner, Winfried. "Interpretive Effects of Head Movement." In Phases of Interpretation, edited by Mara Frascarelli, 45-71. Berlin: Mouton de Gruyter, 2006.

Márquez, Miguel Fuster. Working with Words: An Introduction to English Linguistics. Valencia: Universities de Valencia, 2011.

Mengistu, Tadesse. "The Noun Phrase in Awgni." MA Thesis, Addis Ababa University, 1984.

Murphy, Eliot. "Reference, Phases and Individuation: Topics at the Labeling-Interpretive Interface." Opticon 1826 17, no. 5 (May 2015): $1-13$.

http://dx.doi.org/10.5334/opt.cn.

Rauh, Gisa. Syntactic Categories. Oxford: Oxford University Press, 2013.

Rizzi, Luigi. "Labeling, Maximality and the Head - Phrase Distinction." The Linguistic Review 33, no. 1 (January 5, 2015): 103-27. https://doi.org/10.1515/ttr-20150016.

. "Notes on Labeling and Subject Positions." In Structures, Strategies and Beyond: Studies in Honour of Adriana Belletti, edited by Cornelia Hamann and Simona Matteini. Amsterdam: John Benjamins, 2015.

Roberts, lan. Agreement and Head Movement: Clitics, Incorporation, and Defective Goals. Cambridge: MA: MIT Press, 2010.

Shlonsky, ur, and Luigi Rizzi. "Criterial Freezing in Small Clauses and the Cartography of Copular Constructions: Theoretical 
Approaches and Empirical

Domains." In Freezing, 29-65.

Geneva: University of Siena, 2015.

https://doi.org/10.1515/9781501504

266-002.

Tadesse, Tamrat. "Process of Ethnic Interaction and Integration in Ethiopian History: The Case of Agua," 6:192-206. Moscow: Nauka Publisher, 1988.

Wiltschko, Martina. The Universal Structure of Categories. Cambridge: Cambridge University Press, 2014.

Yasui, Miyoko. An Order-Free Representation of Syntactic Structure and the Head- Parameter. Dokkyo: Dokkyo University Press, 2006.

Yimam, Baye. Amharic Grammar. Addis Ababa: E.M.P.D.A, 1986. 